\title{
STAPHYLOCOCCAL SCALDED SKIN SYNDROME IN NEONATE
}

\author{
B. T. Priya ${ }^{1}$, A. Krishnaveni', K. Rajkumar', M. Vijaya Anand ${ }^{4}$
}

${ }^{1}$ Assistant Professor, Department of Dermatology, Kilpauk Medical College. ${ }^{2}$ Assistant Professor, Department of Dermatology, Kilpauk Medical College.

${ }^{3}$ Assistant Professor, Department of Dermatology, Kilpauk Medical College.

4 Professor, Department of Dermatology, Kilpauk Medical College.

\section{ABSTRACT}

Staphylococcal Scalded Skin Syndrome [SSSS] is primarily a disease of infants and children. The initial event is usually a localized staphylococcal infection. This may be in the skin or at a distant or 'occult' site. We are reporting a rare case of SSSS in a 28 days old neonate following a staphylococcal breast abscess in the mother.

\section{KEYWORDS}

Exfoliative Toxin, Nikolsky Sign, Scalded Skin Syndrome, Staphylococcal Infection.

HOW TO CITE THIS ARTICLE: Priya BT, Krishnaveni A, Rajkumar K, et al. Staphylococcal scalded skin syndrome in neonate. J. Evolution Med. Dent. Sci. 2016;5(62):4395-4396, DOI: 10.14260/jemds/2016/1003

\section{INTRODUCTION}

Staphylococcal scalded skin syndrome is considered part of a spectrum of staphylococcal toxin-mediated infections, which includes bullous impetigo and toxic shock syndrome. Outbreaks occurring in neonatal nurseries are usually secondary to asymptomatic carriage of a toxigenic strain of $\mathrm{S}$. aureus by healthcare workers or parents. ${ }^{1}$ Factors such as renal failure, malignancy, immunosuppression or alcohol abuse predispose adults to the disease. ${ }^{2}$ although the disease has been described in normal young adults. ${ }^{3}$

\section{CASE REPORT}

A 28-day-old full-term male baby presented to us with reddish skin eruptions and blisters present all over the body of 4 days duration. Mother was also admitted in our hospital for her for high fever and painful swelling and pus formation of her right breast. The mother has developed breast tenderness and swelling 2 weeks back, which gradually increased to abscess formation and ulceration over her right breast. She had breastfed the baby till the admission in our hospital. She was started on Inj. Cefotaxime 1 gm IV BD, analgesics, paracetamol, antihistamines. Cleaning and dressing up of the wound was done daily. Pus for culture and sensitivity was sent from the pus for mother. On examination the baby was febrile and irritable. Erythematous macular eruptions well developed were seen all over the body. Umbilicus was erythematous and swollen with pus discharging. Vesicles and bullae were seen over the knees, back and gluteal region. Nikolsky sign was positive. Baby was also admitted in the neonatal unit. All blood investigations, blood culture, Tzanck tests were done. Pus culture and sensitivity was done from 2 sites for the baby. One from umbilicus and second from the fluid from the vesicles and bullae. Baby was started empirically on Inj. Amoxicillin and Cloxacillin. Total count was 17,000 with $80 \%$ neutrophilic leucocytosis and others within normal limits. Tzanck test and blood culture were negative. Pus culture reports from mother

Financial or Other, Competing Interest: None.

Submission 07-03-2016, Peer Review 22-07-2016,

Acceptance 27-07-2016, Published 04-08-2016.

Corresponding Author:

Dr. B. T. Priya,

5B, Uma Complex, Kelly's Junction,

Kilpauk, Chennai-600010.

E-mail: priyachiran@gmail.com

DOI: $10.14260 /$ jemds/2016/1003 and baby confirmed growth of Staphylococcus aureus organism from the breast abscess of mother and umbilical pus from the baby. Culture report came negative from the vesicle lesions. Organisms were highly sensitive for Cephalosporins and tetracyclines. Baby was started on Inj. Cefotaxime twice a day after stopping Inj. amoxicillin and cloxacillin. Skin lesions resolved in 10 days with healing of umbilical lesion. Mother was also discharged after 2 weeks after complete healing of the breast abscess.

\section{DISCUSSION}

Exfoliative Toxins (ETs A and B) are made by certain strains of S. aureus (Phage Group 2). ${ }^{4}$ ETs are serine proteases that bind to the cell adhesion molecule desmoglein 1 and cleave it, resulting in a loss of cell-cell adhesion which is the cause of the clinical manifestations. ${ }^{5}$

The initial event is usually a localized staphylococcal infection. In our patient following the breast abscess in the mother baby developed umbilical sepsis, which progressed to SSSS. Cutaneous tenderness is a very important sign. Tenderness can be often so severe that infants will refuse to lie down or allow anyone to hold them. Within 1 to 2 days, the rash progresses from an exanthematous scarlatiniform to a blistering eruption. Very superficial tissue paper-like wrinkling of the epidermis progresses to large flaccid bullae in flexural and periorificial surfaces.

A positive Nikolsky sign can be elicited. Large sheets of the epidermal surface are typically shed, revealing a moist underlying erythematous base. The cutaneous process usually resolves spontaneously or faster with antibiotics and superficial desquamation. The condition usually heals within 7-14 days. Swabs and cultures of blister fluids do not usually grow the staphylococci, as the blisters are mediated by the toxins which are disseminated haematogenously. The staphylococci may be isolated from the original septic site.

The principal diagnostic problem is distinguishing generalized SSSS from Toxic Epidermal Necrolysis (TEN). ${ }^{6}$ Frozen sections can rapidly differentiate the superficial subgranular acantholysis in SSSS and the characteristic fullthickness epidermal necrosis and dermal-epidermal separation seen in TEN. ${ }^{7}$

Staphylococcal scalded skin syndrome in a neonate following a breast abscess in the mother is one of the rare presentations and only few cases are published. 
We are presenting this case for its uniqueness and to make aware of this rare and serious diagnosis that is commonly seen in children which needs early diagnosis, treatment and

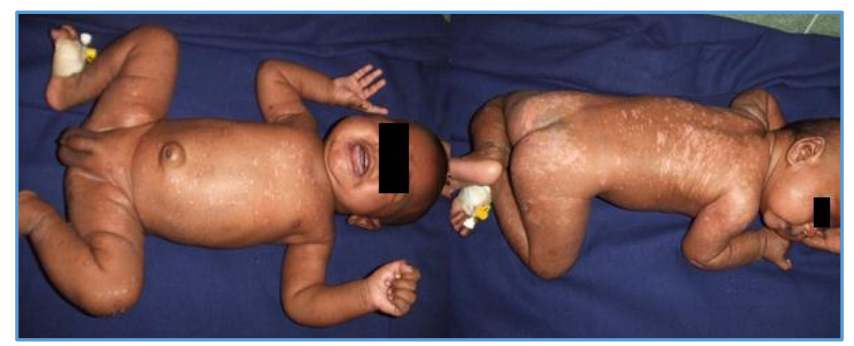

Fig. 1: Baby After Recovery, 3 Weeks Later

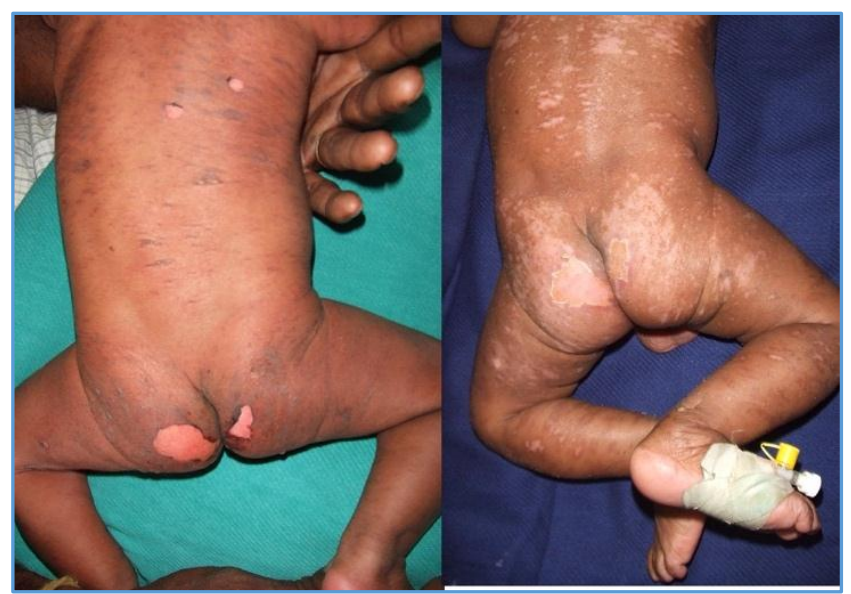

Fig. 2: Nikolsky Sign: Peeling of Skin Same Site After Recovery

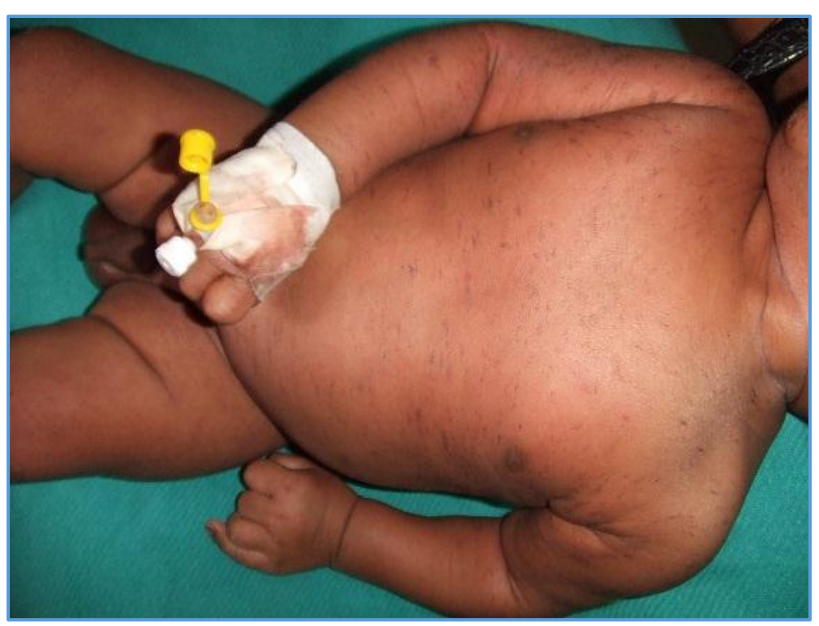

Fig. 3: Eruptions Over Body

\section{REFERENCES}

1. Curran JP, Al-Salihi FL. Neonatal staphylococcal scalded skin syndrome: massive outbreak due to an unusual phage type. Pediatrics 1980;66(2):285-90.

2. Patel GK, Varma S, Finlay AY. Staphylococcal scalded skin syndrome in healthy adults. $\mathrm{Br} \mathrm{J}$ Dermatol 2000;142(6):1253-5.

3. Mockenhaupt M, Idzko M, Grosber M, et al. Epidemiology of staphylococcal scalded skin syndrome in Germany. J Invest Dermatol 2005;124(4):700-3.

4. Ladhani S, Joannou CL, Lochrie DP, et al. Clinical, microbial and biochemical aspects of the exfoliative toxins causing staphylococcal scalded-skin syndrome. Clin Microbiol Rev 1999;12(2):224-242. supportive care, provided which the baby can make complete recovery.

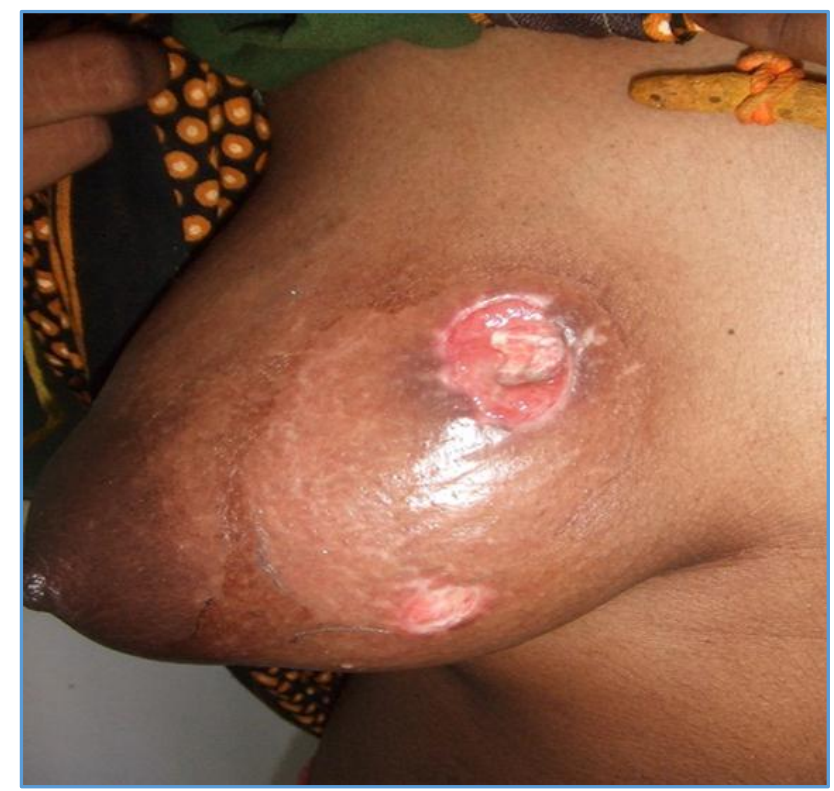

Fig. 4: Breast Abscess in Mother

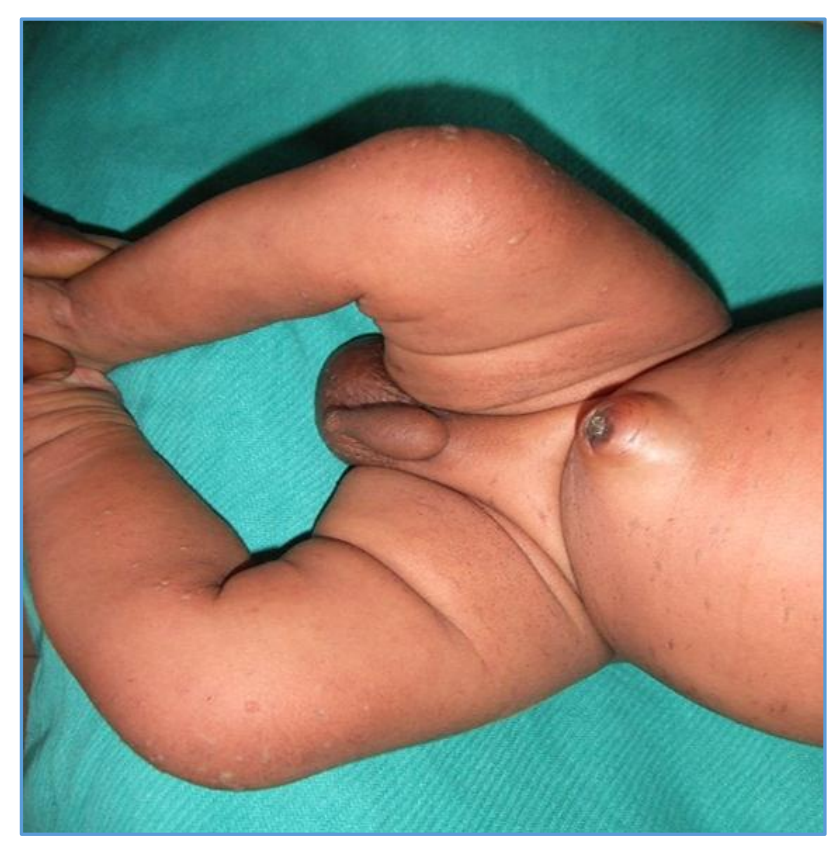

Fig. 5: Umbilical Sepsis

5. Amagai M, Matsuyoshi N, Wang ZH, et al. Toxin in bullous impetigo and staphylococcal scalded-skin syndrome targets desmoglein 1. Nat Med 2000;6(11):1275-7.

6. Lyell A. Toxic epidermal necrolysis: an eruption resembling scalding of the skin. $\mathrm{Br} \mathrm{J}$ Dermatol 1956;68(11):355-61.

7. Amon RB, Dimond RL. Toxic epidermal necrolysis. Rapid differentiation between staphylococcal-and drug-induced disease. Arch Dermatol 1975;111(11):1433-7. 